\title{
Case Analysis and Thinking of Scheme Analysis Based on Mobile New Systems in Psychological Education
}

\author{
Chun-Hung Ko, Shun Tang, and Yucheng Shen (iD) \\ College of Education and Science, Huaiyin Normal University, Huaian 223300, Jiangsu, China \\ Correspondence should be addressed to Yucheng Shen; 20180008@wzu.edu.cn
}

Received 26 August 2021; Revised 24 November 2021; Accepted 7 December 2021; Published 31 December 2021

Academic Editor: Sang-Bing Tsai

Copyright (c) 2021 Chun-Hung Ko et al. This is an open access article distributed under the Creative Commons Attribution License, which permits unrestricted use, distribution, and reproduction in any medium, provided the original work is properly cited.

\begin{abstract}
Education has improved the ideological style of society, improved people's spiritual quality, and improved people's lifestyle, provided sincere principles for people's enthusiasm, and provided goals and political power for people's ideals and contemporary thinking. Thinking diagrams are a teaching method that helps people sort out their ideas and solve difficult problems and can clearly connect the relationships between various concepts. This article is intended to explore the auxiliary effects of case analysis and thinking in psychological education in the context of mobile new systems. Through a series of research methods such as literature research method, action research method, mathematical statistics method, etc., finally 110 elementary and middle school students with psychological problems in a city conducted an experimental survey, and SPSS software was used to analyze and research the statistical results. The experimental results of this article show that psychological teachers use mental icons to provide psychological counseling to students with psychological problems. The success rate of counseling can be increased by $5-10 \%$. It can be seen that an effective method of thinking diagram education can promote the better development of students, and it can also help more teenagers with psychological problems to get rid of psychological barriers.
\end{abstract}

\section{Introduction}

1.1. Background. Nowadays, the educational backgrounds and times of elementary and middle school students are different, and they are born with a lack of knowledge of psychology. In addition, it is difficult to train in psychological counseling ability. Through systematic research and exploration of the school psychological counseling education, in the subsequent psychological counseling training, the psychological counseling training mode and reasonable thinking diagrams are used as the unity and focus of the explanation, which provides a certain degree for psychological theory and psychological counseling.

In recent years, mental health has generally developed. In countries such as Europe and the United States, mental health education is produced after the development of psychological counseling and psychotherapy to a considerable extent. Mental health education is considered to be the product of reform and improvement after people are dissatisfied with traditional psychological counseling.
Western scholars believe that psychological counseling only improves treatment and ignores development; it only serves a small number of students who have problems but ignores the majority of "normal" students. Psychological counseling only passively waits for the occurrence of problems to remedy them but does not actively prevent them from occurring.

Helping students master core knowledge in mental health and raising students' attention to psychological education is one of the core issues of modern psychological mathematics education. Core knowledge teaching is the center of classroom teaching. Teachers should achieve high efficiency in the teaching process and not only help students master the complete psychological core knowledge system, but also help students develop good learning habits and develop their communication skills and creativity. Thinking is a tool for efficient construction of core knowledge systems. This tool is based on brain science, multi-intellectual, and knowledge visualization, and with center point, ray, and branch as keywords, each branch forms a connection. These 
basic characteristics show the relationship between knowledge. Combining psychological education core knowledge and thinking maps can effectively help students master complex knowledge networks and clarify the relationship between the level of knowledge points, thereby improving students' logical thinking ability and promoting students' cultivation of innovative thinking.

With people's understanding and mastery of mind maps, mind maps can be applied to all aspects of life and work, including learning, writing, communication, speech, management, meetings, etc., using the learning ability and clarity brought by mind maps. The way of thinking will improve many people's behaviors:

(1). Increase your learning speed and efficiency exponentially and make you learn new knowledge faster and review and integrate old knowledge.

(2). Stimulate your association and creativity and make you integrate all kinds of scattered wisdom and resources into a system.

(3). Let you form a systematic study and thinking habit and enable you to achieve many goals you want to achieve, including quick note-taking, smoothly passing the exam, easy communication, speech, writing, management, etc.

(4). Let you have superhuman learning ability, learn from the outstanding characters you like, and surpass your idols and opponents.

1.2. Significance. Mind maps are an efficient way of thinking to help people express their ideas. This is a very simple but very efficient thinking tool. People tend to use it to help them remember and organize their thinking. We believe that visual mind maps will be very useful for our psychological counseling and education.

1.3. Related Work. Gao Yanlu randomly divided 54 students in the integrated Chinese and Western medicine class into an experimental group and a control group, with 27 students in each group. The control group used ordinary clinical trials to guide the teaching, and the experimental group used the thinking diagram teaching mode for teaching. They used the test results to perform statistical analysis on two groups of students and explored the value of applying thinking diagram teaching methods in clinical diagnostic laboratories [1]. But they did not apply the teaching method of thinking illustration to psychological counseling and education. Psychologists such as Champagne believe that education and mental health consultation are an important part of the work of primary and secondary school students. They introduced the intervention strategies for students with psychological problems in the form of case studies and used the viewpoints of social welfare and power in the workplace and discussed their research directions and research programs as well as the program's impact on psychological counseling education [2]. For related education and mental health consulting work, case analysis can be used to intervene students' psychological problems. However, they only studied the impact of mental health education on ideological education and did not in-depth study how to use thinking diagrams to influence education and psychological counseling. Liu takes apartment-style students as the research object and carries out secondary mental health consultation. This will not only help the problem teenagers reunderstand themselves, but also promote the overall development of the moral, intellectual, physical, and beauty sides of primary and secondary school students, which has played a good educational role [3]. However, they have ignored the important role and influence of thinking diagrams on psychological counseling and ideological education.

1.4. Innovation. This article sorts out the close relationship between education and psychological counseling and mental illustration, establishes the role of current ideological and political workers in psychological counseling in primary and secondary school education, promotes global thinking on the effectiveness of ideological and political education in primary and secondary schools, and promotes the development of education. Secondly, it has implemented the mission of "Moral Education" and "Psychological Education" proposed by the Party Group of the Ministry of Education of the Communist Party of China in the "Ideological and Political Education Quality Improvement Project Implementation Outline." Finally, on the basis of constructing the psychological counseling ability structure of ideological and political workers in elementary and middle schools, many suggestions for educational approaches are put forward, for example, how to educate students to create effective thinking diagrams and scientifically improve the theoretical guidance of psychological counseling educators for primary and secondary school students.

\section{Methods of Case Analysis and Thinking of Scheme Analysis Based on Mobile New Systems in Psychological Education}

2.1. Statistical Experiment Method. This article will divide 110 teenagers with psychological problems into the experimental group and the control group. Before the experiment, both two groups will be pretested by a psychological questionnaire survey, and then the psychological counseling teacher will use the mind icon to conduct the experimental group psychological counseling intervention [4, 5]; the control group only allows psychological teachers to conduct ordinary oral psychological counseling. The scope of work for psychology teachers is as follows:

(1). Psychological counseling teachers should follow the counseling principles of "respect for understanding, being sincere and confidential, and helping others to help themselves."

(2). Punctuality and trustworthiness and enthusiastic service make one's own work a real need for the healthy growth of students and strive to maintain the reputation of the school's psychological counseling room. 
(3). Psychological counseling teachers should continuously learn related knowledge of mental health education to improve their professional quality, counseling skills, and service level.

(4). Psychological counseling teachers must strictly follow the principle of confidentiality.

(5). Psychological counseling teachers should be aware of their own limitations and should promptly refer cases beyond their capabilities.

After the psychological counseling is over, both two groups are separately tested to verify the effect of the mental diagram on the psychological counseling of primary and middle school students. After the experiment, a self-evaluation survey was carried out on the members of the experimental group, and the evaluation of the students in the experimental group on the psychological counseling under the thinking diagram mode was investigated $[6,7]$. Two weeks after the experiment, the life satisfaction questionnaire was used to test the satisfaction of the students in the experimental group. The formula to be used in this statistical experiment is as follows: The research method mind map is shown in Figure 1.

Because the mind map is closely related to the divergent thinking of the brain, its main function is to improve human memory and divergent thinking. For students with poor abstract thinking ability, the unique "image memory" of mind maps helps students remember knowledge more easily. The scope of application is very wide. There have been surveys conducted by foreign blogs and they summarized the 10 common areas of mind mapping: to-do matters, preparation for presentation, taking notes, problem solving, project planning, decision making, knowledge management, project management, and personal thinking and writing. The scope of application of mind maps can be briefly summarized into these three scenarios: life, study, and work. In daily life, we can use mind maps to make plans, checklists, travel plans, and so on.

(1) Product-to-difference correlation coefficient: The product-to-difference correlation coefficient is abbreviated as the correlation coefficient, which is a statistical indicator of data statistics, used to reflect the degree of correlation between experimental objects and experimental data. The specific product difference correlation coefficient is shown in formula (1):

$$
Z_{\mathrm{MN}}=\frac{\sum M_{i} N_{i}-1 / x\left(\sum M_{i}\right)\left(\sum N_{i}\right)}{\sqrt{M_{i}^{2}-1 / x\left(\sum M_{i}\right)^{2}} \sqrt{N_{i}^{2}-1 / x\left(\sum N_{i}\right)^{2}}} .
$$

The value of the correlation coefficient is between -1 and +1 , that is, $-1 \leq r \leq+1$. Its nature is as follows:

(i) When $r>0$, the two variables are positively correlated; when $r<0$, the two variables are negatively correlated.

(ii) When $|r|=1$, it means that the two variables are completely linearly related, that is, a functional relationship. (iii) When $r=0$, it means the wireless correlation between the two variables.

(2) Sample size estimation: The sample size refers to the number of units contained in the sample, usually represented by $n$. This is a very important concept in sampling. The sample size is directly related to the accuracy of the conclusion estimation. In other words, under certain overall conditions, the larger the sample size, the smaller the typical error in statistical inference. On the contrary, the sample size is the smaller and the estimation error is the larger $[8,9]$. The specific formula is shown in (2):

$$
m=\left(\frac{t(\alpha / 2) \cdot S}{d}\right)^{2} .
$$

(3) Levene variance test

$$
S=\frac{1}{\mathrm{NW}_{J}} \frac{\sum_{m=1}^{i} B_{m}\left(X_{m}-\bar{X}\right)^{2}}{i-1} .
$$

(4) Synthesis of sample difference

$$
\theta_{x}=\sqrt{\frac{\sum_{j=1}^{k}\left(m_{j} \theta_{j}^{2}\right)+\sum_{j=1}^{k} m_{j}\left(\overline{Y_{i}}-Y_{x}\right)^{2}}{m_{1}+m_{2}+\cdots+m_{k}} .}
$$

(5) The $t$-test, also called the student's $t$-test, is mainly used for statistics where the standard deviation of the normal distribution is unknown and the experimental data sample is small. The $t$-test is to use the $t$ distribution to formulate inference to estimate the probability of the difference between two groups, so that we can compare the data between two groups for obvious differences $[10,11]$.

$$
t=\frac{\bar{N}-\mu}{\sigma_{n} / \sqrt{m-1}} .
$$

The shape of the $t$ distribution curve is related to the size of $n$ (to be precise with the degrees of freedom df). Compared with the standard normal distribution curve, the smaller the degree of freedom $\mathrm{df}$, the flatter the $t$ distribution curve, the lower the middle of the curve, and the higher the tails of the curve; the greater the degree of freedom df, the closer the $t$ distribution curve to the normal distribution curve. When the degree of freedom $\mathrm{df}=\infty$, the $t$ distribution curve is the standard normal distribution curve. The single population $t$-test is to test whether the difference between a sample mean and a known population mean is significant. When the population distribution is a normal distribution, for example, the population standard deviation is unknown and the sample size is less than 30 , then the deviation statistics of the sample mean and the population mean are distributed at $t$.

(6) Confidence interval of the overall mean 

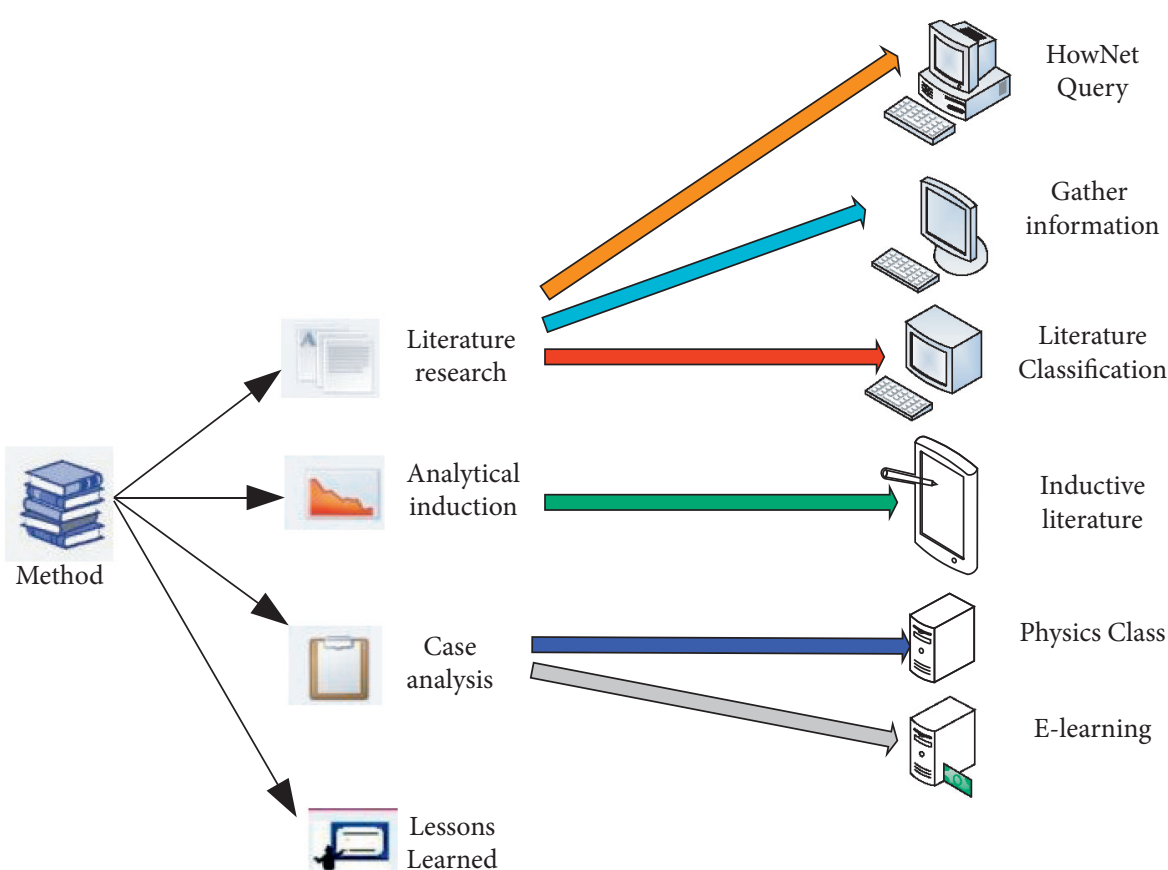

FIgURE 1: Research method mind map.

$$
\left[\bar{Y}-\frac{Z(\alpha / 2) \cdot \sigma}{\sqrt{n}}, \bar{Y}+\frac{Z(\alpha / 2) \cdot \sigma}{\sqrt{n}}\right]
$$

(7) The normalized processing formula is used in the statistics and calculations of experimental data. The definition of normalization: normalization is to limit the processed data (through a specific algorithm) to a specific degree required. Normalization refers to identity and unity. The specific formula is shown in formula $(7)[12,13]$ :

$$
D_{J}=\frac{b_{j}}{\sum_{z=1}^{n} a_{z}} .
$$

If we do not perform normalization processing, then the distribution of each batch of training data is different. From a large perspective, the neural network needs to find a balance among these multiple distributions. From a small perspective, the input data distribution of the layer network is constantly changing, which will also cause each layer of the network to find a balance point.

Introduce the concept of location error:

$$
\text { location_error }_{i}=\sqrt{\left\|\widetilde{x}_{i}-x_{i}\right\|_{2}}, \quad i=1, \ldots, N .
$$

Introduce the concept of average error:

average_error $=\frac{\sum_{i=1}^{N} \text { location_error }_{i}}{N}=\frac{\sum_{i=1}^{N} \sqrt{\left\|\tilde{x}_{i}-x_{i}\right\|_{2}}}{N}$.
The standard deviation of the position error represents the consistency of the positioning accuracy of the algorithm: standard_deviation $=\sqrt{\frac{1}{N} \sum_{i=1}^{N}}(\text { location_error }- \text { average_error })^{2}$.

Use the Global Energy Ratio (GER) to measure the positioning accuracy of the algorithm:

GER $=\frac{\sqrt{\sum_{i<j}\left(\operatorname{dist}_{\text {est }}\left(s_{i}-s_{j}\right)-\operatorname{dis}_{\text {true }}\left(s_{i}-s_{j}\right) / \text { dist }_{\text {ture }}\left(s_{i}-s_{j}\right)\right)^{2}}}{N(N-1) / 2}$.

According to the principle that the RF signal attenuates with the propagation distance, sampling and fitting are used to obtain the function relationship with the distance. The commonly used RF signal attenuation model is

$$
P(d)[\mathrm{dBm}]=P\left(d_{0}\right)[\mathrm{dBm}]-\eta 10 \lg \left(\frac{d}{d_{0}}\right)+x_{\sigma}
$$

Amend equation (12) and propose an attenuation model: $P(d)[\mathrm{dBm}]=P\left(d_{0}\right)[\mathrm{dBm}]-\eta 10 \lg \left(\frac{d}{d_{0}}\right)- \begin{cases}n W \times \mathrm{WAF}, & n W<C, \\ C \times \mathrm{WAF}, & n W \geq C .\end{cases}$

Introducing the node distance, the two signal propagation speeds, and the signal arrival time, their relationship is as follows: 


$$
\begin{aligned}
& T_{1}=\frac{d}{c_{1}}, \\
& T_{2}=\frac{d}{c_{2}} .
\end{aligned}
$$

2.2. Literature Research Method. The method of literature research mainly refers to the method of collecting and borrowing literature to complete the scientific understanding and recognition of facts through literary research. The author collects domestic and foreign books and documents on psychological counseling and thinking diagrams and documents on how to conduct psychological education counseling to primary and middle school students and interprets, organizes, and analyzes the data to provide theoretical support and information orientation for the thesis $[14,15]$. The knowledge management map is shown in Figure 2.

The general process of the literature method includes five basic links, namely, proposing topics or hypotheses, researching design, collecting documents, collating documents, and conducting literature reviews. The proposed topic or hypothesis of the literature method refers to the idea of analyzing and recategorizing the relevant literature based on the existing theories, facts, and needs. Research design must first establish research objectives. Research objectives refer to the use of operable definitions to design the content of a topic or hypothesis into specific, operable, and repeatable literature research activities, which can solve specific problems and have certain characteristics.

2.3. Action Research Method. Action research method refers to a research method in which teachers use various research methods and techniques according to specific operating procedures in a natural and hands-on teaching environment, and its main purpose is to solve the problem of psychological education and guidance $[16,17]$.

\section{Experiments to Case Analysis and Thinking of Scheme Analysis Based on Mobile New Systems in Psychological Education}

3.1. Experiment Preparation. We have invited well-known pedagogy and psychology experts in the urban area to provide special training to psychological counseling teachers in primary and secondary schools. Only when psychological counseling teachers are good at thinking and summarizing can they continue to make progress and achieve self-development over time. However, the daily work of psychological counseling teachers is very busy, so "keeping good records after class" is usually not enough. So, how do we find opportunities to promote self-improvement of these experiences and reach the depth of education and research? Exciting thinking icons can better solve these problems; thinking icons can collect basic information in time and increase the importance of education and research $[18,19]$. The detailed education and research work is in-depth, which has laid a solid foundation for the formation of "promising" teachers. The specific approach is shown in Figure 3.

The action research method combines pure educational scientific research experiments with quasi-educational scientific research experiments, combines the characteristics of the humanities of educational scientific research with the characteristics of natural science experiments, and uses the theories, methods, and techniques of educational science to examine and guide education. Teaching practice raises the educational and teaching experience to a theoretical level, but it relies on its own educational and teaching practice.

The action research method is an exploratory research method that adapts to educational reform in a small scale. Its purpose is not to establish theories and general rules, but to continuously explore and improve on the problems in educational activities and educational practice and solve practical problems in education. Action research combines reform actions with research work and is closely linked to specific reform actions in educational practice.

3.2. Experimental Subjects and Experimental Process. In order to verify the effect of this study on the psychological counseling and education, 110 elementary and middle school students with psychological problems after a psychological questionnaire survey in a certain city were selected in this experiment to be divided into two classes, one as the experimental class and the second as the experimental class. In order to control the class, there are 55 students in each class. Before the experiment, the scores of the psychological questionnaire survey of these students are very close to each other.

Psychological counseling, which adopts the thinking diagram education method for the teaching of the experimental class, is a relatively different educational method from the traditional psychological counseling. With students as the main body of study, the steps of psychological counseling by psychological teachers through the mental diagram education method shown in Figure 4 can allow problem teenagers to recognize the reality and understand themselves and improve the success rate of psychological counseling for problem teenagers.

\section{Result of Psychological Counseling Experiment}

4.1. Statistics and Analysis of Pretest and Posttest Data. Collect and analyze the data in the pre- and posttest experiments. First of all, the psychological questionnaire survey scores of primary and middle school students before the experiment were taken as the preexperiment test, and SPSS software was used for analysis to determine that there was no significant difference in the psychological questionnaire survey scores between the experimental class and the control class before the experiment. The experimental class uses psychological counseling under the educational method of thinking diagram mode, while the control class uses oral psychological counseling. The students in two different classes participated in a new round of psychological 


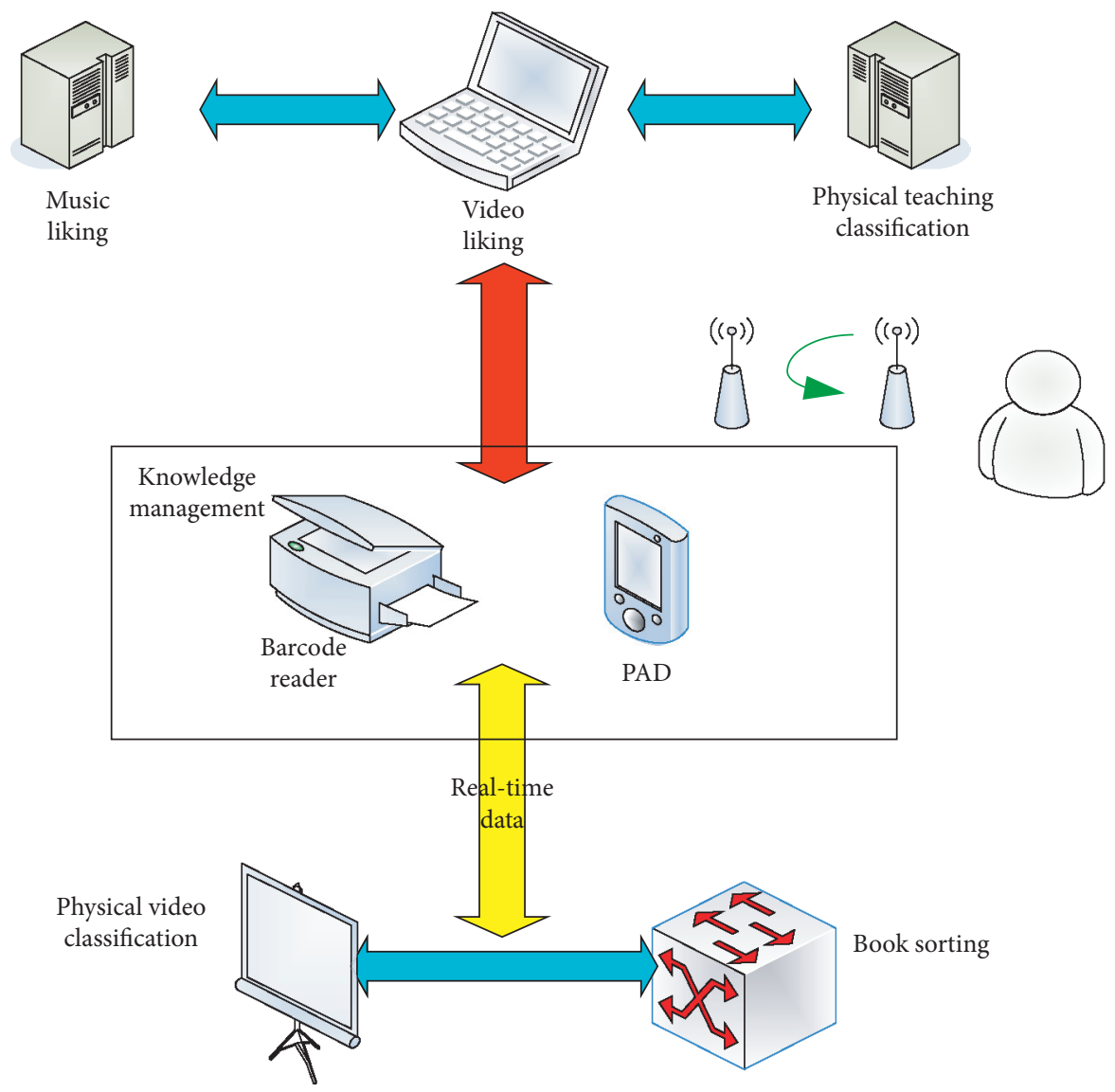

Figure 2: The knowledge management map.

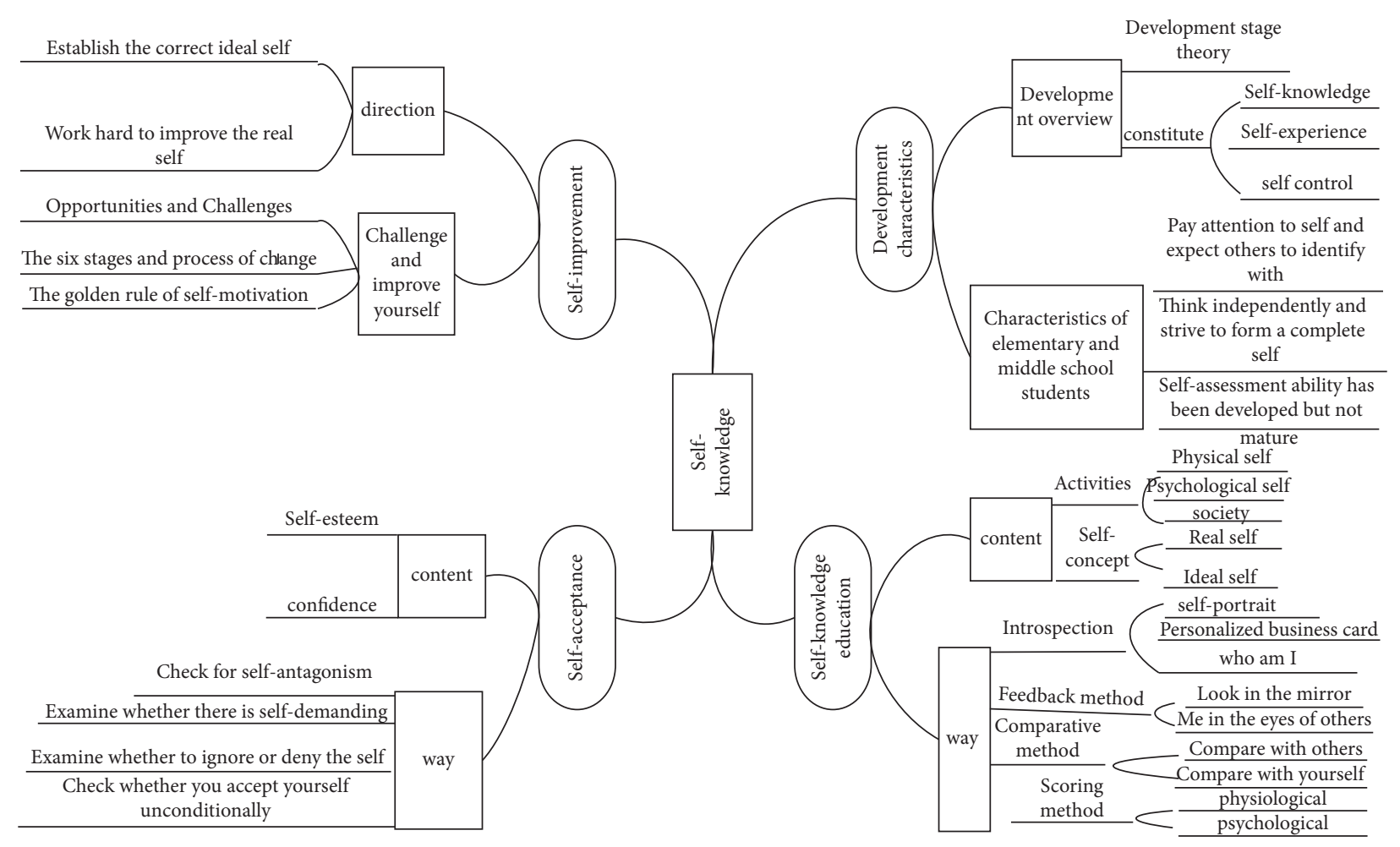

Figure 3: Psychological counseling teacher's guidance plan for primary and middle school students. 


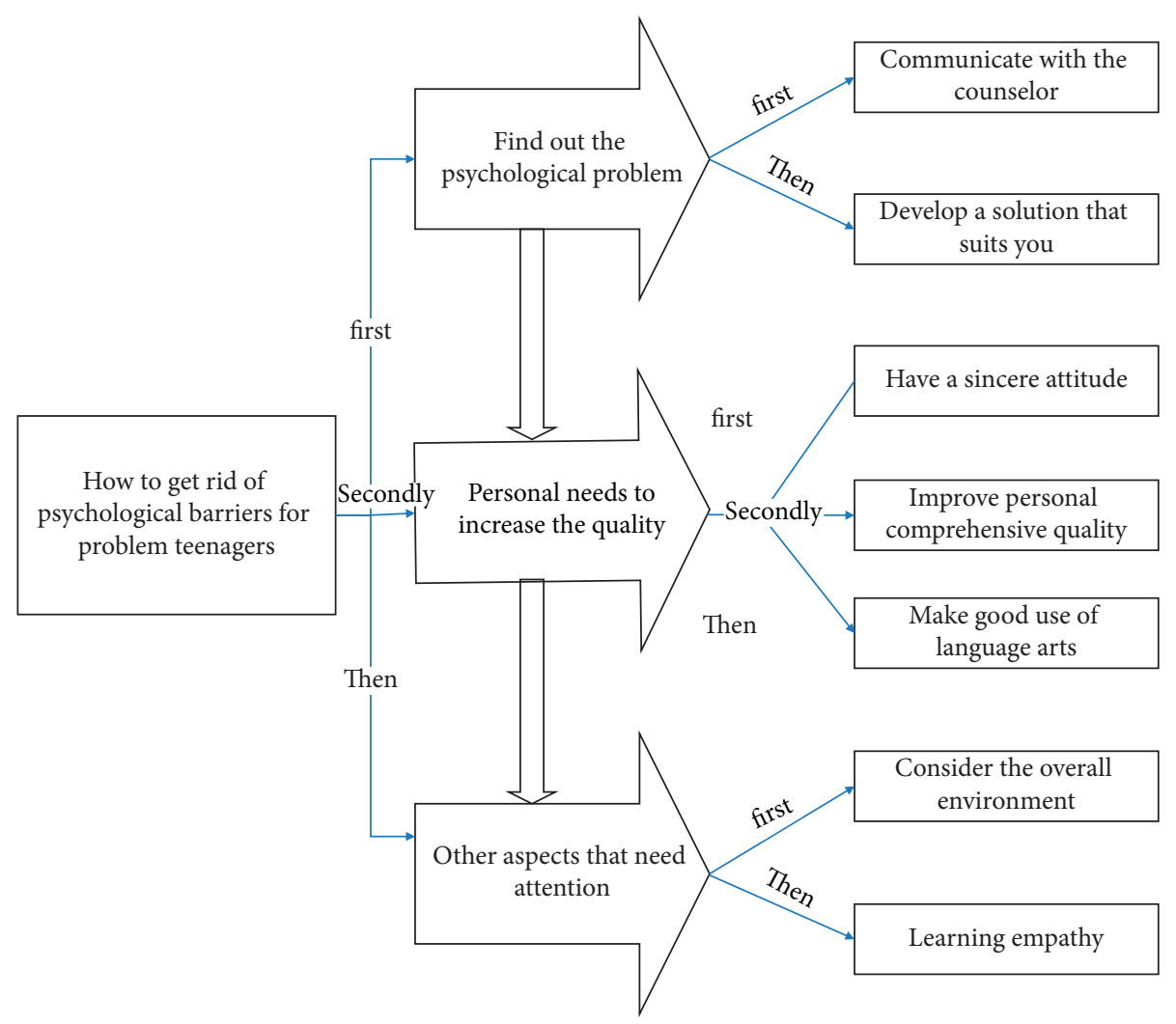

FIGURE 4: Several key steps and programs to solve psychological problems.

questionnaires after the psychological counseling was over. At this time, it was about two weeks before two different classes applied their own psychological counseling mode.

4.1.1. Pretest. Through the use of SPSS software, firstly, the students in two different classes (converted into a hundredpoint system), that is, the pretest questionnaire survey scores, are statistically analyzed (Tables 1 and 2).

4.1.2. Posttest. Also use SPSS software to analyze the psychological questionnaire scores (converted to a percentile system) of two groups after two weeks, that is, the posttest.

From the data in the above table, we can see that, in the scores after the test, the values assuming equal variances are $2.584,0.135,-0.245,59,0.145$, etc., while the values assuming that the variances are not the same are $-0.236,56$, $0.045,3.5471,1.6578$, etc.; the values are generally compound estimates. The main source of the experimental data set is the statistical data of a certain class of the experimental elementary school.

According to the abovementioned independent $t$-test and Levene test sample data, sng is 0.045 , which is less than 0.05 , indicating that there is a significant difference in the questionnaire scores after the psychological counseling experiment of the experimental class and the control class. The average score of the experimental class is higher than the average score of the control class. Therefore, adopting the psychological counseling mode of thinking diagrams can improve the success rate of psychological counseling for young people.
4.2. Life Satisfaction of Students in Experimental Group and Control Group after the Experiment. Two weeks after the psychological counseling, we conducted a questionnaire survey on life satisfaction among a total of 110 boys and girls in two groups. A total of 110 questionnaires were distributed and 110 were recovered. Among them, 5 invalid questionnaires were eliminated, and 105 valid questionnaires remained. The results of the survey are shown in Figure 5:

Observing the results of the survey in Figure 5, we can see that the total score of life satisfaction is 100 . The scores of the students in the experimental class for friendship satisfaction, family satisfaction, and school satisfaction are close to full marks, and they are all higher than those of the control class. Some students in the experimental class think that the mental illustration has greatly changed their emotions and thoughts and think that the psychological counseling of the mental illustration mode can greatly help their interpersonal communication. In addition, there are a small number of experiments. The students in the class believe that through this psychological counseling, they have become more confident and can actively express and share their inner feelings with others.

4.3. Survey of Satisfaction with Psychological Counseling under the Mode of Thinking Illustration. Two weeks after the end of the psychological counseling, we conducted a questionnaire survey on whether the thinking diagram teaching mode is helpful to problem students with a total of 88 psychological counseling teachers of different ages in the city. A total of 88 questionnaire surveys were issued and 88 were retrieved. 
TABLE 1: Independent sample $t$-test and Levene test for pretest scores.

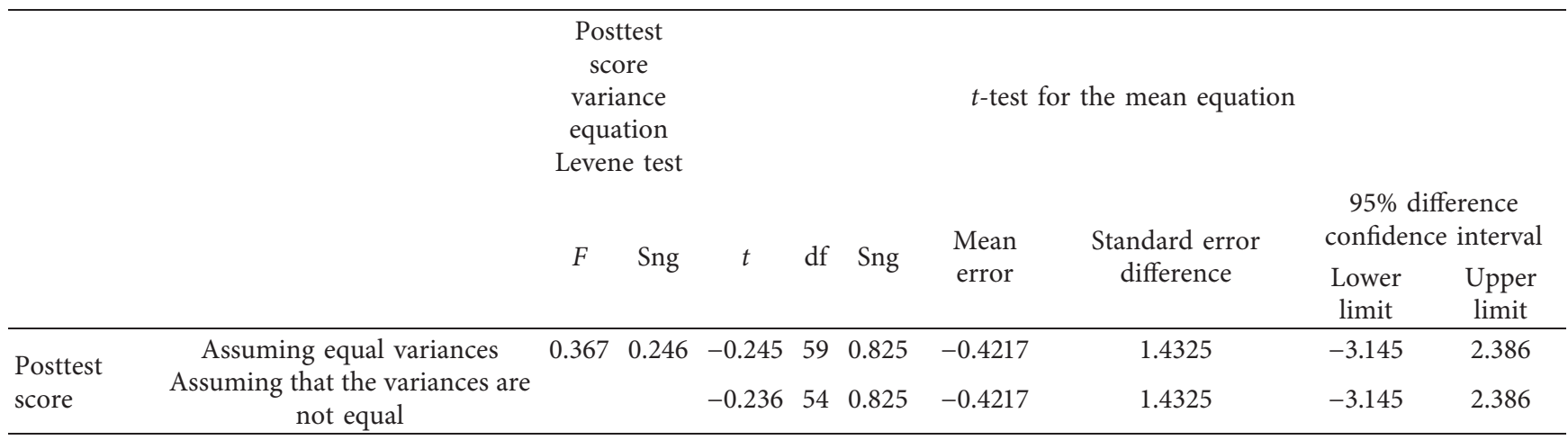

TABLE 2: Independent sample $t$-test and Levene test for posttest results.

\begin{tabular}{|c|c|c|c|c|c|c|c|c|c|}
\hline \multirow{2}{*}{\multicolumn{2}{|c|}{ Posttest score variance equation Levene test }} & \multicolumn{7}{|c|}{$t$-test for the mean equation } & \multirow[b]{2}{*}{$\begin{array}{c}95 \% \text { difference } \\
\text { confidence } \\
\text { interval }\end{array}$} \\
\hline & & $F$ & Sng & $t$ & $\mathrm{df}$ & Sng & $\begin{array}{l}\text { Mean } \\
\text { error }\end{array}$ & $\begin{array}{l}\text { Standard error } \\
\text { difference }\end{array}$ & \\
\hline Lower limit & Upper limit & & & & & & & & \\
\hline \multirow{2}{*}{$\begin{array}{l}\text { Posttest } \\
\text { score }\end{array}$} & Assuming equal variances & 2.584 & 0.135 & -0.245 & 59 & 0.045 & 3.5471 & 1.6578 & $-3.145 \quad 6.3245$ \\
\hline & $\begin{array}{c}\text { Assuming that the variances are not } \\
\text { equal }\end{array}$ & & & -0.236 & 56 & 0.045 & 3.5471 & 1.6578 & -3.1458 .3355 \\
\hline
\end{tabular}

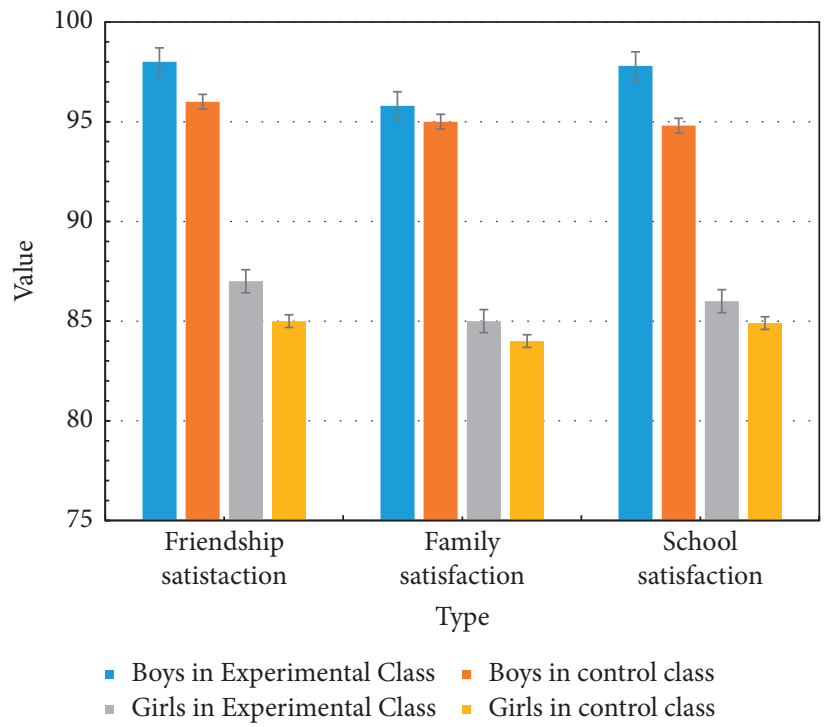

FIGURE 5: Life satisfaction questionnaire survey.

Among them, 3 invalid questionnaires are eliminated, and 85 valid questionnaires remain. The statistical results are shown in Figure 6.

It can be seen from Figure 6 that more than $60 \%$ of psychological teachers think that the mode of thinking illustration is of great help to the teaching of psychological counseling and that thinking illustration can help problem students point the direction, understand themselves, and clarify their goals; only no more than $10 \%$ of psychological counseling teachers believe that the thinking illustration mode is not helpful for psychological counseling teaching. It is believed that psychological counseling still depends on the teacher's own teaching ability and the students' own comprehension ability and the ability to overcome difficulties and solve problems. Thinking diagrams are not helpful to psychological counseling. At the same time, through statistics on the data of the questionnaire survey, we can see that the success rate of psychological counseling through the mind map education model has increased by $40 \%$, and the rejection rate for psychological counseling has been reduced by nearly $62 \%$, which has effectively improved related problems.

A summary of the number of related documents of the mind map (2006 2016) is shown in Figure 7. 


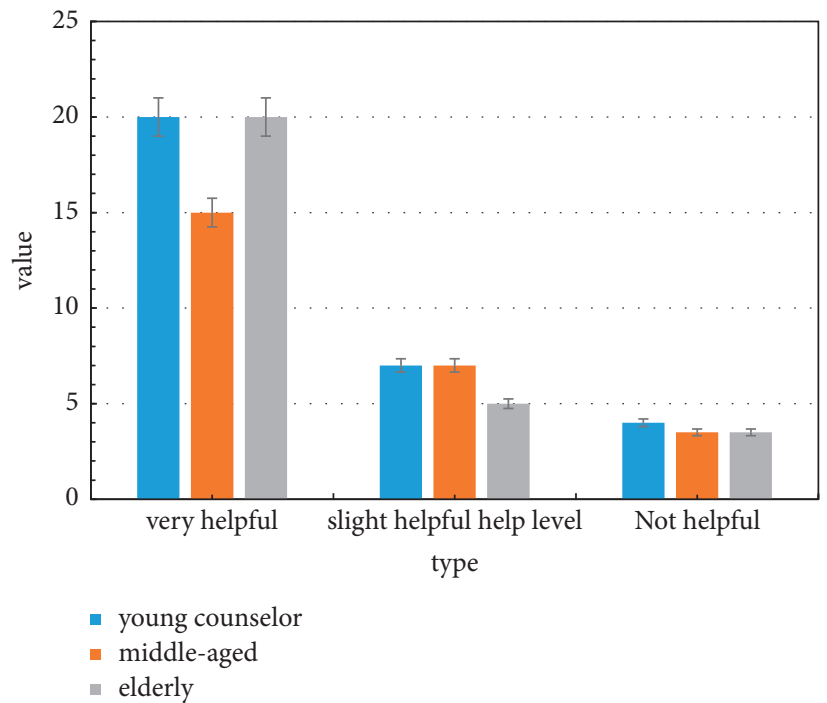

FIGURE 6: Questionnaire survey of satisfaction with the teaching mode of thinking diagram.

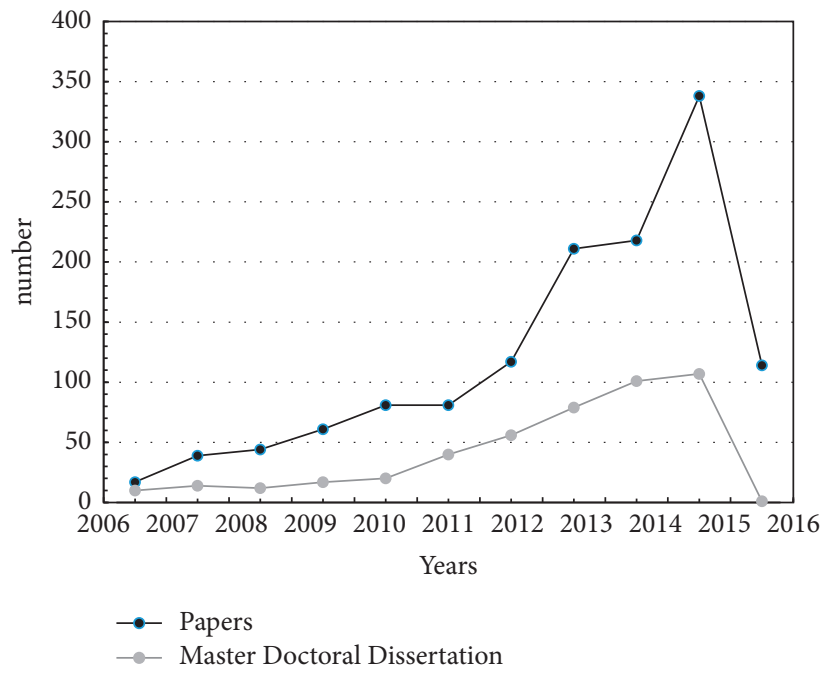

FIGURE 7: A summary of the number of related documents of the mind map (2006 2016).

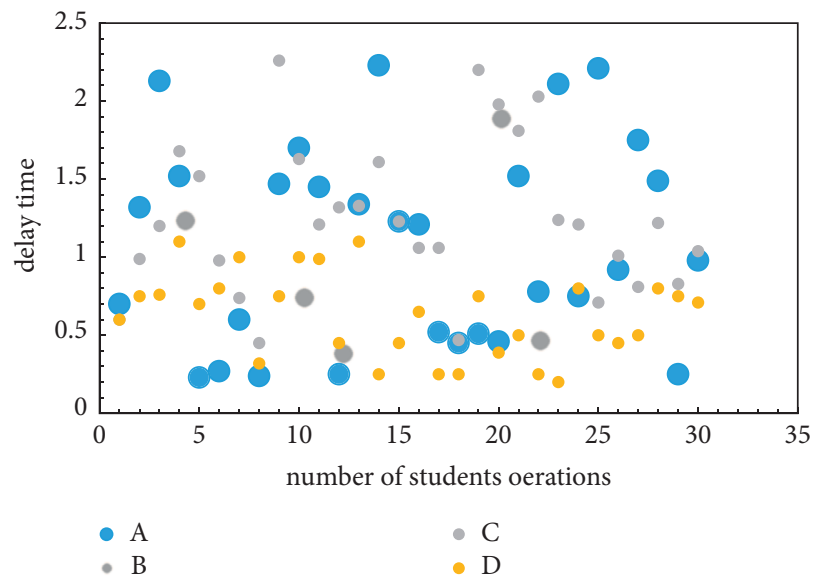

FIGURE 8: System availability index test results. 
TABLE 3: The division of specific cognitive level of mathematics curriculum standards in primary and secondary schools.

Content Level

(1) Functions and related concepts such as function domains, function values, function representations, and constant value functions

(2) The concept of proportional function, inverse proportional function, image of proportional function, and inverse proportional function

(3) Basic properties of proportional function and inverse proportional function

(4) Concept and image of linear function

(5) Basic concepts of linear functions

(6) The basic concept of quadratic function

(7) The image and basic properties of the quadratic function

(8) Use the method of undetermined coefficients to find the analytical expressions of the proportional function, the inverse proportional function, the linear function, and the quadratic function

(9) Application of a function

TABLE 4: The subject distribution of the literature at different times.

\begin{tabular}{cccccccccccc}
\hline & Politics & Chinese & History & Science & Math & Physical & Biology & Chemistry & Geography & English & Others \\
\hline 2006 & 1 & - & - & - & - & 1 & - & 1 & - & - & - \\
2012 & 1 & - & - & 5 & 2 & 7 & 9 & 7 & 3 & 7 & 1 \\
2015 & 8 & 10 & 11 & 12 & 15 & 18 & 28 & 35 & 47 & 82 & 4 \\
\hline
\end{tabular}

TABLE 5: The test of the normality of the scores of the students in the control group.

\begin{tabular}{lccccccc}
\hline & \multirow{2}{*}{ Class } & \multicolumn{3}{c}{ Kolmogorov-Smirnov } & \multicolumn{3}{c}{ Shapiro-Wilk } \\
& & Statistics & df & Sig & Statistics & df & Sig \\
\hline Grade & Control group & 075 & 62 & 200 & 987 & 62 & 730 \\
\hline
\end{tabular}

TABLE 6: The test of the normality of the scores of the students in the experimental group.

\begin{tabular}{ccccccrr}
\hline & \multirow{2}{*}{ Class } & \multicolumn{3}{c}{ Kolmogorov-Smirnov } & \multicolumn{3}{c}{ Shapiro-Wilk } \\
& & Statistics & df & Sig & Statistics & df & Sig \\
\hline Grade & Experimental group & 064 & 58 & 200 & 979 & 58 & 0418 \\
\hline
\end{tabular}

TABLE 7: The independent sample $t$ hypothesis test.

\begin{tabular}{ccccccccccc}
\hline & \multicolumn{4}{c}{ Levene test of variance equation } & \multicolumn{3}{c}{$t$-test for the mean equation } \\
& & $F$ & Sig. & $t$ & df & Sig. & Mean difference & Standard error & Lower limit & Higher limit \\
\hline \multirow{2}{*}{ Grades } & H0 & 0.052 & 0.820 & 0.073 & 118 & 0.942 & 0.26029 & 3.58415 & -6.83730 & 7.35788 \\
& H1 & & & 0.073 & 116.939 & 0.942 & 0.26029 & 3.58415 & -6.84466 & 7.36523 \\
\hline
\end{tabular}

System availability index test results are shown in Figure 8.

The division of specific cognitive level of mathematics curriculum standards in primary and secondary schools is shown in Table 3.

The subject distribution of the literature at different times is shown in Table 4.

The scores of the students in the control group and the experimental group are in accordance with the normal distribution. Therefore, statistical analysis can be done on the results of the students in the control group and the experimental group.

The test of the normality of the scores of the students in the control group is shown in Table 5.
The test of the normality of the scores of the students in the experimental group is shown in Table 6 .

The $P$ value (i.e., Sig value) of the students' scores in the control group and the experimental group is 0.2 , that is, $P>0.05$, which is in line with the normal distribution.

The independent sample $t$ hypothesis test is shown in Table 7:

\section{Conclusions}

All in all, although the thinking icon tool has a great reputation in China, there are also many related works and documents covering various fields such as economics, culture, and education. The divergence of thinking and the 
visibility of knowledge can particularly arouse the attention of the education circle. Compared with ordinary teaching methods, the mind map education method is closely related to divergent thinking in the brain, and its main function is to improve human memory and divergent thinking. At the same time, for students with poor abstract thinking ability, the unique "image memory" of mind maps helps students remember knowledge more easily. Therefore, the thinking icon is both a tool for "teaching" and a tool for "learning," so using thinking the picture shows psychological counseling and education is the arrow on the string. Researchers in the education field and even front-line teachers are eager to try this, and they have also contributed a large number of valuable research papers and works. However, due to the difficulty of the operation of the thinking diagram itself, most of the research is concentrated on higher education. Psychological counseling and education for primary and middle school students have not yet been popularized, so we should vigorously promote the teaching method of thinking diagrams, so that more teachers can learn to use thinking diagrams for psychological counseling and education of primary and middle school students and improve students' ability to resist stress and make students get rid of psychological barriers as soon as possible, and only from this can primary and middle school students have a happy childhood.

\section{Data Availability}

No data were used to support this study.

\section{Conflicts of Interest}

The authors declare that there are no conflicts of interest regarding the publication of this article.

\section{References}

[1] Y. Gao, "Study on the application value of mind mapping teaching method in the diagnosis of clinical experiment," China Continuing Medical Education, vol. 008, no. 023, pp. 10-12, 2016.

[2] M. Champagne, "Diagrams and alien ways of thinking," Studies In History and Philosophy of Science Part A, vol. 75, no. Jun, pp. 12-22, 2019.

[3] X. Liu, "Research on the application of "tree analysis diagram" to the teaching of English argumentative writing of the Chinese EFL learners," English Language Teaching, vol. 11, no. 3, pp. 26-33, 2018.

[4] J. L. Plotkin and J. A. Goldberg, "Thinking outside the box (and arrow): current themes in striatal dysfunction in movement disorders," The Neuroscientist: A Review Journal Bringing Neurobiology, Neurology and Psychiatry, vol. 25, no. 4, pp. 359-379, 2019.

[5] D. H. B. Welsh, W. L. Tullar, and H. Nemati, "Entrepreneurship education: process, method, or both?" Journal of Innovation \& Knowledge, vol. 1, no. 3, pp. 125-132, 2016.

[6] N. d. P. Arruda Filho and N. D. Paula, "The agenda 2030 for responsible management education: an applied methodology," International Journal of Management in Education, vol. 15, no. 2, pp. 183-191, 2017.
[7] A. Lindsay and M. Langevin, "Psychological counseling as an adjunct to stuttering treatment: clients' experiences and perceptions," Journal of Fluency Disorders, vol. 52, no. 3, pp. 1-12, 2017.

[8] C. Jia and L. Dan, "On ways to infiltrate ecological civilization education into ideological and political education of higher vocational colleges," Science Education Article Collects, vol. 56, no. 4, pp. 337-341, 2016.

[9] M. Capurso and B. Ragni, "Psycho-educational preparation of children for anaesthesia: a review of intervention methods," Patient Education and Counseling, vol. 99, no. 2, pp. 173-185, 2016.

[10] E. Antón, G. Thierry, A. Goborov, J. Anasagasti, and J. A. Duñabeitia, "Testing bilingual educational methods: a plea to end the language-mixing taboo," Language Learning, vol. 66, no. S2, pp. 29-50, 2016.

[11] I. M. Shawket, "Educational methods instruct outdoor design principles: contributing to a better environment - ScienceDirect," Procedia Environmental Sciences, vol. 34, no. 5, pp. 222-232, 2016.

[12] Wang-Sheng and W. Jie-Feng, "Research on the innovation of ideological and political education of university students in the we-media and big data era," in Proceedings of the International Conference on Measuring Technology \& Mechatronics Automation, pp. 403-407, IEEE, Changsha, Hunan, China, January 2017.

[13] A. Basem Mohmed, "The efficiency of the psychological counseling field training program at yarmouk university from seen by counselor trainees," International Journal of Religious Education, vol. 43, no. 1, p. 1, 2019.

[14] H. Cai and X. Gu, "Supporting collaborative learning using a diagram-based visible thinking tool based on cognitive load theory," British Journal of Educational Technology, vol. 50, no. 2, pp. 12-23, 2019.

[15] M. J. Eppler and S. Kernbach, "Dynagrams: enhancing design thinking through dynamic diagrams," Design Studies, vol. 47, no. nov, pp. 91-117, 2016.

[16] W. Brenner and F. Uebernickel, Design Thinking for Innovation, Dynagrams: Enhancing Design Thinking Through Dynamic Diagrams, Chapter 6, Springer, Berlin, Germany, Springer, 2016 .

[17] L. K. Schoenenberger, S. Bayer, and J. P. Ansah, "Emergency department crowding in Singapore: insights from a systems thinking approach," Sage Open, vol. 4, no. 27, pp. 40-43, 2016.

[18] T. S. Omotayo, P. Boateng, O. Osobajo, A. Oke, and L. Obi, "Systems thinking and CMM for continuous improvement in the construction industry," International Journal of Productivity and Performance Management, vol. 69, no. 2, pp. 271296, 2019.

[19] K. Lu, "Distribution of the two-sample t-test statistic following blinded sample size re-estimation," Pharmaceutical Statistics, vol. 15, no. 3, pp. 208-215, 2016. 